\title{
Efficacy of Tongue Stimulation in Neurorehabilitation- A Narrative Review
}

\author{
Jayaprakash Jayavelu ${ }^{1}$, Jasobanta Sethi $^{2}$, Sahil Kohli ${ }^{3}$, Tariq Matin ${ }^{4}$ \\ ${ }^{I}$ PhD Scholar, Amity Institute of Physiotherapy, Amity University and Chief Physiotherapist, Narayana \\ Superspecialty Hospital, Gurugram, ${ }^{2}$ Director and Professor, Amity Institute of Physiotherapy, Amity University, \\ ${ }^{3}$ Consultant Neurology, Narayana Superspecialty Hospital, Gurugram, ${ }^{4}$ Senior Consultant, Neurointervention,
} Narayana Superspecialty Hospital, Gurugram

\begin{abstract}
Introduction: The tongue is being represented bilaterally in the motor homunculus of the brain. Tongue has been used as an effective interface to send signals to central nervous system. The purpose of this article is to review all articles related to tongue stimulation in neurological rehabilitation.

Method: All studies including case studies, cohort studies, experimental studies and reviews, which dealt with tongue stimulation in neurological conditions during the period between 2010 and 2020, were included in the study.

Results: Tongue Stimulation has been used effectively $\mathrm{n}$ rehabilitation for improving balance in patients with vestibular disorders, multiple sclerosis patients, spinal cord injury patients and stroke patients. Tongue Stimulation has also been used to improve motor recovery in stroke patients.

Conclusion: Tongue stimulation becomes a novel mode of stimulation in inducing neuroplasticity and can be used in wide variety of neurological patients. Further researches needs to be done on the effect of tongue stimulation on upper extremity rehabilitation in stroke patients.
\end{abstract}

Keywords: Hand Gesture, Speech, Tongue Movements.

\section{Introduction}

Tongue has been represented in both hemisphere and recovery of tongue in brain damaged patients is faster compared to limb recovery. This unique representation of the tongue has been used in various types of rehabilitation.

The purpose of this review is to review all articles which has dealt with tongue stimulation on neurological patients.

\footnotetext{
Corresponding Author:

Dr. Jasobanta Sethi

Director and Professor, Amity Institute of

Physiotherapy, Amity University, Noida, Uttar Pradesh

e-mail: jsethi@amity.edu
}

\section{Method}

Literature search for case studies, cohort studies, experimental trials and reviews on the tongue stimulation, hypoglossal stimulation and periglossal stimulation on neurological patients were performed in the following online databases: PubMed, EMBASE, The Cochrane Library, and Scopus. Three of the authors independently screened all papers titles and abstracts for relevance and reviewed by one reviewer.

\section{Results}

After appropriate screening, 11 articles published during the period between 2010 and 2020 have been taken for this review.

Wildenberg et al (2010) did a study on balance dysfunction of twelve patients and found that cranial nerve non-invasive neuromodulation involving tongue stimulation improved the balance of the patients by 
increasing activity within the dorsal pons. ${ }^{1}$ Similar results were reported on nine balance impaired patientswho were given tongue stimulation for 10 days and their sensory organization testing scores improved. ${ }^{2,3,4}$

Fourteen weeks of balance training along with tongue stimulation were given to twenty chronic multiple sclerosis patients and their dynamic gait index improved significantly. (Mitchell E Tyler et al, 2014). ${ }^{5}$

In a study done by Brittany M. Young et al, sixteen subjects received up to 15 two-hour sessions of interventional therapy using an EEG-guided braincomputer interface (BCI) device, which incorporated visual display, tongue stimulation, and functional electrical stimulation as feedback. These BCI therapy sessions were scheduled over the course of up to 6 weeks with no more than three sessions per week.Functional MRI, Action Research Arm Test (ARAT), 9-Hole Peg Test (9-HPT), and Stroke Impact Scale (SIS) domains of Hand Function (HF) and Activities of Daily Living (ADL) were assessed before and after the therapy. The correlations noted between changes in functional(FC) measures and changes in behavioral outcomes indicate that both adaptive and maladaptive changes in FC may develop with this therapy ${ }^{6,7}$ Similar results were found in nineteen stroke patients with upper extremity impairment. ${ }^{8}$

Fourteen Multiple Sclerosis patients (7 in active tongue stimulation and 7 in sham stimulation group) received intensive physical therapy and working memory training for 14 weeks. Active group showed improvement in sensory organization testing scores. Results showed that tongue stimulation can enhance motor performance and working memory while also driving neuroplasticity. (Gabriel Leonard et al, 2017) ${ }^{9}$

Rosaleena Mohanty et al (2018) did a study on twenty chronic-stage stroke subjects exhibiting persistent upper-extremity motor deficits and they were given intervention using a closed-loop neurofeedback BCI device for 3 weeks. Functional MRI, Action Research Arm Test, Nine-Hole Peg Test, and Barthel Index as well as subjective measures including the Stroke Impact Scale were assessed. Higher number of strengthening functional changes in comparison to the ones weakening between pre- and post-therapy in functional MRI suggests a greater overall positive impact of BCI intervention on stroke recovery at a whole-brain level. ${ }^{10,11}$

\section{Discussion}

Tongue stimulation has been used in various patient categories with primarily sensory-driven balance deficits: people with vestibular loss, peripheral neuropathy, mild traumatic brain injury, and older adults, as well as people with stroke, Parkinson's disease, and ataxia ${ }^{13}$

Loss of motor function is a common deficit following brain insult and often manifests as persistent upper extremity (UE) disability which can affect a survivor's ability to participate in activities of daily living. ${ }^{12}$

Brain computer interface therapy has been developed in addition to tongue stimulation for improving motor functions in cerebrovascular accident patients. ${ }^{6,10,11,14,15,16}$

\section{Conclusion}

Tongue Stimulation has been safely used in wide category of neurological as well as other non neurological patients. Further research can be done to find out the effect of tongue movement and/or stimulation in improving various motor deficits in stroke patients, creating new pathway for recovery.

Funding: This paper received no sources of funding or sponsorship and there is no financial disclosure.

\section{Conflict of Interest: None declared}

Acknowledement: I have to thank my family and friends for supporting me to write this review article.

Ethical Clearance: This review has been done to support the experimental study which was approved by institutional ethics committee of Narayana Health.

\section{References}

1. Wildenberg J C, Tyler M E, Danilov Y P,Kaczmarek K A, Meyerand M E. Sustained cortical and subcortical neuromodulation induced by electrical tongue stimulation. Brain Imaging and Behavior 2011; 4: 199-211. doi: 10.1007/s11682-010-9099-7

2. Wildenberg J C, Tyler M E, Danilov Y P, Kaczmarekc K A, and MeyerandM E. Highresolution fMRI detects neuromodulation of individual brainstem nuclei by electrical tongue stimulation in balance impaired individuals. NeuroImage 2011; 56: 2129-2137. doi: 10.1016/j. neuroimage.2011.03.074 
3. Wildenberg J C, Tyler ME, Danilov Y P, Kaczmarek $\mathrm{K}$ A,Meyerand $\mathrm{M}$ E. Altered Connectivity of the Balance Processing Network After Tongue Stimulation in Balance-Impaired Individuals. Brain Connectivity 2013; Volume 3: Number 1.

4. Wildenberg JC, Tyler ME, Danilov Y P, Kaczmarek K A, Meyerand M E. Electrical Tongue Stimulation Normalizes Activity Within the Motion-Sensitive Brain Network in Balance-Impaired Subjects as Revealed by Group Independent Component Analysis. Brain Connect. 2011 Sep; 1(3): 255-265. doi: 10.1089/brain.2011.0029

5. Tyler ME, Kaczmarek KA, Rust KL, Subbotin A M, Skinner K L, and Danilov Y P. Non-invasive neuromodulation to improve gait in chronic multiple sclerosis: a randomized double blind controlled pilot trial. Journal of NeuroEngineering and Rehabilitation 2014; 11: 79. http://www. jneuroengrehab.com/content/11/1/79

6. Young B M, Nigogosyan Z, Remsik A, Walton L M, Song J, Nair V A, Grogan S W, Tyler M E, Edwards D F, Caldera K, Sattin J A, Williams J C, Prabhakaran V. Changes in functional connectivity correlate with behavioral gains in stroke patients after therapy using a brain-computer interface device. Frontiers in Neuroengineering July 2014; Volume 7: Article 25, 1. www.frontiersin.org

7. Young B M, Nigogosyan Z, Walton L M, Remsik A. Dose-response relationships using braincomputer interface technology impact stroke rehabilitation. Front Hum Neurosci. 2015; 9: 361. Published online 2015 Jun 23. doi: 10.3389/ fnhum.2015.00361. PMCID: PMC4477141.

8. Young B M, Stamm J M, Song J, Remsik A B, Nair V A, Tyler M E, Edwards D F, Caldera K, Sattin J A, Williams J C, Prabhakaran V. Brain-Computer Interface Training after Stroke Affects Patterns of Brain-Behavior Relationships in Corticospinal Motor Fibers. Front Hum Neurosci. 2016; 10: 457. Published online 2016 Sep 16. doi: 10.3389/ fnhum.2016.00457. PMCID: PMC5025476

9. Leonard G, Lapierre Y, Chen J K, Wardini R, Crane J and Ptito A. (2017). Noninvasive tongue stimulation combined with intensive cognitive and physical rehabilitation induces neuroplastic changes in patients with multiple sclerosis: A multimodal neuroimaging study. Multiple Sclerosis JournalExperimental, Translational and Clinical. January - March 1-9. 2017
10. Mohanty R, Sinha A M, Remsik A B, Dodd K C, Young B M, Jacobson T, McMillan M, Thoma J, Advani H, Nair V A, Kang T J, Caldera K, Edwards D F, Williams J C, and Prabhakaran V. Early Findings on Functional Connectivity Correlates of Behavioral Outcomes of Brain-Computer Interface Stroke Rehabilitation Using Machine Learning. Front Neurosci. 2018; 12: 624. Published online 2018 Sep 11. doi: 10.3389/fnins.2018.00624. PMCID: PMC6142044

11. Mohanty R, Sinha A M, Remsik A B, Dodd K C, Young B M, Jacobson T, McMillan M, Thoma J, Advani H, Nair V A, Kang T J, Caldera K, Edwards D F, Williams J C, and Prabhakaran V. Machine Learning Classification to Identify the Stage of Brain-Computer Interface Therapy for Stroke Rehabilitation Using Functional Connectivity. Front Neurosci. 2018; 12: 353. Published online 2018 May 29. doi: 10.3389/fnins.2018.00353.

12. Remsik A B, Williams L, Gjini K, Dodd K, Thomas J, Jacobson T, Walczak M, McMillan M, Rajan S, Young B M, Nigogosyan Z, Advani H, Mohanty R, Tellapragada N, Allen J, Mazrooyisebdani M, Walton L M, Van Kan P L E, Kang T J, Sattin J A, Nair V A, Edwards D F, Williams J C, Prabhakaran V. Ipsilesional $\mathrm{Mu}$ Rhythm Desynchronization and Changes in Motor Behavior Following Post Stroke BCI Intervention for Motor Rehabilitation. Frontiers in Neuroscience 2019; March; Volume 13: Article 53

13. Lawless H T, Stevens D A, Chapman K W, Kurtz A. Metallic Taste from Electrical and Chemical Stimulation. Chem Senses. Author manuscript; available in PMC 2005 Dec 6.Published in final edited form as: Chem Senses. 2005 Mar; 30(3): 185-194. Published online 2005 Mar 1. doi: 10.1093/chemse/bji014.

14. Liegl K P, Rust K L and Smith R O. Introduction to the Portable Neuromodulation Stimulation Stimulator (PONS ${ }^{\mathrm{TM}}$ ) Device and effects on balance and gait for individuals with traumatic brain injuries. Resna Annual Conference 2013.

15. Young B M, Nigogosyan Z, Walton L M, Song J, Nair V A, Grogan S W, Tyler M E, Edwards D F, Caldera K, Sattin J A, Williams J C, Prabhakaran V. Case report: post-stroke interventional BCI rehabilitation in an individual with preexisting sensorineural disability. Front Neuroeng. 2014; 7 : 18. Published online 2014 Jun 24. doi: 10.3389/ 
fneng.2014.00018. PMCID: PMC4067954

16. Remsik A, Young B, Vermilyea R, Kiekoefer L, Abrams J, Elmore S E, Schultz P, Nair V, Edwards D, Williams J, Prabhakaran V. A review of the progression and future implications of braincomputer interface therapies for restoration of distal upper extremity motor function after stroke. Expert Rev Med Devices. Author manuscript; available in PMC 2017 May 1.Published in final edited form as: Expert Rev Med Devices. 2016 May; 13(5): 445-454. doi: 10.1080/17434440.2016.1174572. PMCID: PMC513169. 